\title{
PENYELENGGARAAN OPERASIONAL ANGGOTA PATROLI JALAN RAYA DALAM MELAKSANAKAN TUGAS PENGAWALAN VVIP MAUPUN VIP DI WILAYAH HUKUM POLDA BALI MENURUT UNDANG-UNDANG NOMOR 22 TAHUN 2009
}

\author{
Berliana Indahsari, Anak Agung Sagung Laksmi Dewi, I Made Minggu Widyantara \\ Fakultas Hukum Universitas Warmadewa, Denpasar-Bali, Indonesia \\ indahsari.berliana@gmail.com, laksmidewi29@gmail.com, mademinggu21@gmail.com
}

\begin{abstract}
Abstrak
Dalam wilayah hukum Polda Bali tentunya juga terdapat pengawalan VIP dan VVIP yang merupakan pengawalan khusus dari Kepolisian untuk kunjungan kerja pejabat pemerintah yang berkunjung ke Negara Kesatuan Republik Indonesia. Dalam melaksanakan kegiatan pendampingan tersebut tentunya harus sesuai dengan standard operating procedure (SOP) yang telah ditetapkan. Penelitian ini bertujuan untuk mengkaji pengaturan hukum mengenai pengamanan pengawalan yang dilakukan anggota Polri dalam perjalanan ke tempat tujuan dan mengungkap sanksi yang diterima anggota Polri dalam melakukan pengawalan yang tidak sesuai dengan standar operasional prosedur. Penelitian ini menggunakan pendekatan hukum normatif terhadap permasalahan dan perundang-undangan. Sumber data yang digunakan adalah data primer dan data sekunder yang diperoleh melalui membaca dan mencatat. Selanjutnya data dianalisis secara deskriptif kualitatif. Hasil penelitian menunjukkan bahwa hak pengawalan juga diatur dalam Undang-Undang Nomor 22 Tahun 2009 Pasal 134 tentang Lalu Lintas dan Angkutan Jalan. Sanksi yang diterima anggota Polri yang tidak menegakkan disiplin dalam pengawalan tertuang dalam Peraturan Pemerintah Republik Indonesia Nomor 2 Tahun 2003 tentang Disiplin Anggota Polri atau sanksi pelanggaran pelaksanaan kode etik profesi Polri sebagaimana diatur dalam Peraturan Kapolri. Nomor 14 Tahun 2011 tentang Kode Etik Profesi Polri.
\end{abstract}

Kata Kunci: Lalu Lintas, Polda Bali, Sanksi

\begin{abstract}
Abstrak
In the jurisdiction of the Bali Police, there are also VIP and VVIP escorts which are special escorts from the Police for working visits of government officials visiting the Unitary State of the Republic of Indonesia. In carrying out these mentoring activities, it must be in accordance with the established Standard Operating Procedure (SOP). This study aimed to examine the legal arrangements regarding the security of escorts carried out by Polri members on the way to their destination and reveal the sanctions received by Polri members in carrying out escorts that are not in accordance with Standard Operating Procedures. This study used a normative legal approach to problems and legislation. Sources of data used were primary data and secondary data obtained through reading and taking notes. Furthermore, the data were analyzed descriptively qualitatively. The results of the study indicated that the right to escort is also regulated in Law No. 22 of 2009 Article 134 concerning Road Traffic and Transportation. Sanctions received by Polri members who do not enforce discipline in escort are contained in Government Regulation of the Republic of Indonesia Number 2 of 2003 concerning Discipline of Polri Members or sanctions for violating the implementation of Polri's professional code of ethics as regulated in National Police Chief Regulation Number 14 of 2011 concerning Polri's Professional Code of Ethics.
\end{abstract}

Keywords: Traffic, Bali Police, Sanctions

\section{PENDAHULUAN}

Pada pelaksanaan tugas, pihak kepolisian sebagai sebuah wadah atau institusi yang sangat berperan, tugas juga fungsinya salah satu ada pada bidang lalu lintas (lantas). Polisi lalu lintas atau Polantas merupakan suatu unsur yang melaksanakan tugas-tugas kepolisian yang salah satunya adalah pengaturan, pengawalan, penjagaan dan juga patroli serta pendidikan dan pembentukan karakter masyarakat dan juga rekayasa lalu lintas, identifikasi serta registrasi kendaraan bermotor atau yang sering disebut sebagai pengemudi, penyidikan dalam hal terjadinya kecelakaan lalu lintas dan juga penegakan hukum yang terjadi dalam bidang lalu lintas itu sendiri, guna memelihara ketertiban, 
kelancaran lalu lintas dan keamanan serta kenyamanan saat berkendara. Pelayanan di bidang lalu lintas dari Polisi kemasyarakat juga dilakukan bertujuan yakni untuk memberikan peningkatan kualitas hidup masyarakat salah satunya dengan mengadakan Satuan Patroli Jalan Raya (Sat PJR).

Bali adalah suatu pulau yang sangat dikenal identik dengan tujuan wisata dunia dan tidak jarang menjadi tempat untuk pelaksanaan suatu kegiatan tingkat nasional ataupun internasional yang tentunya menyebabkan terjadinya kepadatan lalu lintas. Seringkali kegiatan yang ada di pulau ini menyangkut tamu VIP/VVIP yang tentunya harus untuk dikawal. Pengawalan lalu lintas ini merupakan suatu giat yang mengadakan penyelenggaraan dalam rangka meningkatkan keamanan yang mana bergerak untuk melindungi serta memberikan rasa aman dan nyaman terhadap jiwa (manusia) dan juga barang (benda). (Junef, 2014). Kegiatan pengawalan atau sering disebut protocol kenegaraan ini mengawal terus menerus seseorang atau benda dari satu tempat ke tempat tujuannya secara terus-menerus dengan menggunakan kendaraan bermotor khusu untuk patrol yang tentunya meningkatkan keamanan pengguna jalan lainnya (Iskandar, 1996).

Pengawalan VVIP ini adalah pengawalan khusus dari pihak Kepolisian yang dipergunakan untuk suatu kunjungan kerja pejabat pemerintahan yang berkunjung ke Negara Kesatuan Republik Indonesia bersama dengan keluarganya seperti Presiden dan juga Wakil Presiden dan Tamu-tamu Negara setingkat kepala negara dari negeri seberang. Sedangkan pengawalan VIP sendiri adalah suatu pengawalan yang dikhususkan untuk para pejabat negara atau pejabat negara asing yang kedudukannya berada di bawah tingkat kepala negara, calon presiden atau calon wakil presiden dan juga Cakada-cawakada TK I/TK II, ambulans yang mengangkut orang-orang sakit yang bersifat emergency, kendaraan yang bertujuan untuk memberikan pertolongan pada kecelakaan lalu lintas, pemadam kebakaran yang sedang melakukan tugasnya, kendaraan yang digunakan untuk menangani bencana alam, rangkaian kendaraan TNI/Polri dan barang-barang berharga atau berbahaya lainnya.

Anggota Polri yang melaksanakan tugas pengawalan pada tamu-tamu VVIP/VIP mempunyai kewenangan yang penuh terhadap pergerakan lalu lintas. Mereka memiliki hak untuk menentukan kemana arah dan juga jalur yang akan dilewati oleh tamu VVIP/VIP itu sendiri. Ada hal-hal yang bisa terjadi saat melaksanakan tugas pengawalan ini yang mana tentunya anggota Polri akan melakukan tindak diskresi. Diskresi merupakan tindakan yang boleh untuk dilakukan oleh Kepolisian Negara Republik Indonesia saat terjadinya gangguan-gangguan pada ketertiban umum yang diperkirakan kedepan akan menimbulkan suatu yang membahayakan dan didalam keadaan tersebut yang tidak dimungkinkan bagi anggota Polri tersebut untuk meminta petunjuk atau atensi dari atasan yang dalam hal bertindak tentunya harus juga memikirkan reaiko dari suatu tindakan yang terjadi.

Saat melaksanakan tugas pengawalan ini tentunya Polri harus memenuhi Standart operational Procedure (SOP) yang tentunya sudah ditetapkan. Berdasarkan Peraturan Ka Korps Lantas Kepolisian No. 2 Tahun 2018 mengenai SOP Pengawalan lalu lintas menyebutkan bahwa pengawalan dilakukan sesuai dengan peran dan fungsi dan mengacu pada bentuk pengawalannya, pelaksanaan pengawalan harus terorganisir dan melalui perencanaan pengawalan lantas, prosedur yang ditetapkan dan juga pengakhiran pengawalan lantas itu sendiri. Penelitian ini bertujuan untuk mengkaji pengaturan hukum tentang pengamanan pengawalan yang dilakukan anggota Polri dalam perjalanan sampai di tempat tujuan dan mengungkapkan sanksi yang diterima anggota Polri dalam pelaksanakan pengawalan tidak sesuai dengan standar operasional prosedur.

Penelitian terdahulu yang relevan dengan penelitian ini mengungkapkan Satuan Lalu Lintas Polres wajib melakukan upaya optimalisasi Dikmas Lantas guna meningkatkan kesadaran pelajar dalam keselamatan berlalu lintas banyak mengalami hambatan. Selanjutnya dalam pemberian sanksi pelanngaran lalu lintas harus sesuai dengan ketentuan Undang-undang (Hanafi, 2017). Untuk meningkatkan kesadaran masyarakat pengguna jalan dalam mematuhi program lalu lintas diupayakan dari petugas mensosialisasikan Undang-undang LLAJ (Anas, 2020); (Jasmine, 2020). Walaupun sudah diteliti terkait prosedur penyelenggaraan operasional Patroli, namun samapai saat ini masih terlihat kegagalan aparat satlantas dalam melakukan rajian. Berkaitan dengan ini, peneliti melakukan Penelitian yang bertujuan untuk mengkaji pengaturan hukum tentang pengamanan pengawalan yang dilakukan anggota Polri dalam perjalanan sampai ditempat tujuan dan mengungkapkan sanksi yang diterima anggota Polri dalam pelaksanakan pengawalan tidak sesuai dengan Standar Operasional Prosedur 


\section{METODE PENELITIAN}

Penelitian ini menggunakan penelitian hukum normatif atau disebut juga kepustakaan karena seluruh pendekatan masalahnya diambil dari refrensi literatur dan modul serta pendekatan masalahnyapun menggunakan perundang-undangan (Soekanto, 1984). yang di konsepkan sesuai dengan yang tertera pada peraturan Perundang-undangan dan juga hukum yang terlibat dikonsepkan sebagai suatu kaidah maupun norma-norma tertulis yang menjadi patokan berprilaku manusia yang dalam hal ini adalah Masyarakat RI yang dianggap pantas dan layak (Amiruddin \& Asikin, 2006). Sedangkan sumber bahan hukum yang digunakan ialah berasal dari sumber bahan hukum sekunder untuk mencari data awal atau informasi, yang lalu mendapatkan landasan teori atau landasan hukum mendapatkan batasan, definisi, arti dari suatu istilah (Ashshofa, 1996).

\section{HASIL DAN PEMBAHASAN}

\section{Pengaturan Hukum tentang Pengamanan Pengawalan yang Dilakukan Anggota Polri dalam Perjalanan Sampai di Tempat Tujuan}

Semua manusia tentunya memiliki hak-hak yang sama dalam menggunakan jalan untuk mobilisasi berlalu lintas. Tanpa membedakan haknya untuk diutamakan dalam beralalu lintas, terkecuali atas dasar peraturan perundang-undangan yang tercantum dan memberikan peluang baru terhadap suatu keperluan tertentu yang mendapatkan suatu tindakan prioritas dalam menggunakan jalan untuk berlalu lintas.

Dalam mewujudkan ketentuan dan ketetapan pada keamanan, kenyamanan, keselamatan dalam berlalu lintas, ketertiban dalam mematuhi rambu-rambu lalu lintas, dan kelancaran berlalu lintas sendiri (Kamseltibcarlantas) terhadap suatu objek yang dikawal dan masyarakat di jalan raya (Karjadi, 1975)

a. Menjaga jalan-jalan yang rentan terjadi kerusakan seperti jembatan agar tidak hancur disebabkan oleh kendaraan yang melintas terlalu berat;

b. Meningkatkan kualitas dan kelancaran serta ketertiban dalam berkendara;

c. Mengatur dan juga ikut menyalurkan dengan tertib segala angkutan barang-barang dan juga penumpang terutama dengan kendaraan umum

Hak-hak utama tersebut diatur secara tertulis dalam Undang-undang Nomor 22 Tahun 2009 tentang Lalu Lintas dan Angkutan Jalan. Dalam pasal 134, pengguna jalan yang mendapatkan haknya yang paling utama untuk tetap didahulukan sesuai dengan urutannya sebagai berikut:

1. Pemadam kebakaran yang menjalankan tugasnya untuk membantu masyarakat;

2. Ambulance yang bersifat urgent untuk mengangkut orang yang sakit;

3. Kendaraan yang digunakan untuk mengangkut suatu kejadian kecelakaan lalu lintas;

4. Tamu Negara setingkat pimpinan yang berkunjung ke Wilayah Indonesia;

5. Iringan jenazah;

6. Kendaraan tertentu yang menurut pertimbangan Negara digunakan untuk penanganan ancaman bom, pengangkut petugas yang akan menyelesaikan huru-hara, angkutan para pasukan keamanan, penanganan bencana alam, dokumen dan uang yang tentunya dianggap penting, pengawalan barang-barang berbahaya dan juga kegiatan masyarakat lainnya yang sudah mendapatkan izin.

Dasar hukum dari kewenangan anggota Polri mengenai pengawalan ini diatur dalam Pasal 12 huruf E Undang-undang Nomor 22 Tahun 2009 untuk melaksanakan suatu penjagaan, pengawalan, pengaturan dan juga patroli kepada suatu kegiatan masyarakat (kepentingan umum) dan juga kepentingan pemerintahan sesuai yang di butuhkan dan juga memberikan kewenangan untuk bisa bertindak sesuai dengan penilaiannya sendiri demi kepentingan umum yang dimaksud.

Dalam UU No. 22 / 2009 dalam Pasal 104 ayat (1) mengatur hal-hal yang memiliki keterikatan dengan Pengutamaan Petugas, yang mangatakan bahwa dalam rangka meningkatkan ketertiban serta kelancaran berkendara dan angkutan jalan, para polisi memiliki kewenangan penuh untuk meberhentikan/menstop arus lalu lintas dan juga para pengguna jalan. Meningkatkan kualitas perjalanan dengan bisa memberikan untuk pengendara untuk jalan terus, mempercepat arus lalu lintas dan juga memperlambatnya serta sampai mengalihkan arus agar tidak terjadi penumpukan kendaraan di satu tempat sehingga menyebabkan kepadatan.

Adapun perencanaan yang dapat dilakukam sebelum melakukan kegiatan pengamanan pengawalan lalu lintas yakni Mendeteksi data-data awal kegiatan pengawalan lalu lintas, 
Menpersiapkan dengan kuat personil anggota Polri yang akan melaksanakan tugas pengawalan, Mempersiapkan sarana dan juga prasarana dalam tugas pengawalan dan Menyiapkan jalur alternatif, survey lokasi dan alur yang akan dilewati saat pengawalan;

Adapun kendala-kendala yang sering terjadi saat melakukan tugas pengawalan, dalam hal ini lah peran anggota Polri sangat diuji guna bisa menyelamatkan objek yang dikawalnya dan melindungi objek tersebut (Romadhon, 2020). Adapun bentuk-bentuk dalam penyelamatan terhadap suatu objek yang dilakukan pengawalan yaitu Membatalkan keberangkatan dalam hal terjadinya suatu kendala sebagai berikut:

a. Menyiapkan rute alternatif atau cadangan untuk jaga-jaga

b. Escape kembali code yang ada

c. Escape atau penyelamatan dengan menggunakan helicopter maupun pesawat udara;

d. Penyelamatan dengan menggunakan kapal laut.

\section{Sanksi yang Diterima Anggota Polri yang Melakukan Tugas Tidak Sesuai dengan Standar Operasional Prosedur}

Instansi Kepolisian merupakan suatu wadah yang dipercaya dapat mengayomi dengan baik, melayani masyarakat dan melindungi masyarakat dan juga menegakkan keadilan, memelihara rasa aman dan nyaman dengan peningkatan ketertiban di kehidupan bermasyarakat. Menurut Tim Pokja Lemdiklat. Dalam rangka menghindari sikap yang tidak diinginkan oleh masyarakat kepada Polri maka tindakan diskresi harus wajib untuk tidak terlalu banyak diterapkan dengan mempertimbangkan asas-asas yakni:

1. Asas kepentingan adalah suatu tindakan yang mewajibkan Polisi untuk melakukan tindakan diskresi, seperti ada suatu kegiatan besar dan polisi setempat membantu untuk pengalihan arus lalu lintas agar tidak macet

2. Asas Tujuan merupakan suatu tindakan dalam pengambilan keputusan yang menciptakan rasa aman dan nyaman dalam kehidupan bermasyarakat yang tentunya dianggap keputusan yang paling tepat untuk menghindari kejadian yang membahayakan, misalnya dalam suatu kejadian kebakaran, Polisi mengambil keputusan untuk merobohkan rumah disamping bangunan yang terbakar, hal ini dilakukan untuk menghindari merembetnya kobaran api;

3. Asas keseimbangan dalam pengambilan keputusan dan juga tindakan harus memikirkan lebih dalam lagi mengenai manajemen resiko yakni dengan sarana yang digpergunakan, besar atau kecilnya gangguan itu, besar atau kecil objek yang akan ditindak. Contohnya seperti menilang pengemudi yang tidak perlu dengan cara kasar, cukup dengan cara yang humanis;

4. Asas Keperluan

Tindakan ini sangat dibutuhkan, contoh: Polisi yang memberhentikan mobilitas di jalan dalam rangka mendahulukan kendaraan yang bersifat vital seperti mobil pemadam kebakaran, ambulance, pengawalan pejabat,dll.

Adapaun tindakan yang dilakukan oleh seorang polisi yang sangat fatal adalah melakukan suatu tindakan tanpa adanya surat perintah (Sprin) pengawalan atau tidak terdapak permintaan resmi untuk pengawalan. Sprin ini juga merupakan bagian dari surat kuasa yang didapatkan polisi oleh atasannya untuk kelengkapan administrasi yang harus digunakan sebelum mejalankan tugas pengawalan. Dalam rangka meningkatkan penegakkan hukum banyak cara yang dipergunakan dan juga disiplin dari anggota Polri salah satunya adalah PP Republik Indonesia No. 1 Tahun 2003 tentang Pemberhentian anggota Polri, PP Republik Indonesia Nomor 3 Tahun 2003 tentang Pelaksanaan Teknis Institusional Peradilan Umum bagi anggota Polri dan juga PP Republik Indonesia Nomor 2 Tahun 2003 tentang Disiplin Anggota Polri.

Dalam rangka pelaksanaan tugas apapun, seluruh anggota Polisi melakukan tindakan berdasarkan dari suatu norma atau peraturan-peraturan dari kesatuan landasan etik (kode etik) ataupun filosofis yang tentunya memiliki keterkaitan yang erat dengan cara berperilaku ataupun cara berucap tentang hal yang dianggap perlu atau wajib, patut ataupun tidak patut, dilarang untuk dilakukan oleh para anggota Polisi dalam pelaksanaan tugas apapun, kewenangan dan juga tanggung jawab yang tentunya sesuai dengan aturan tertulis yakni PerKAPOL No. 14 tahun 2011 tentang Kode Etik Profesi Polri. Walau begitu tetap pasti ada anggota polisi yang tindakannya dalam melaksanakan tugas tidak sesuai dengan kode etik Polri. Anggota Polri yang melakuakn pelanggaran tentunya akan 
diberlakukan suatu sanksi oleh komisi kode etik profesi Polri, yakni berupa

a. Teguran secara lisan

b. Prilaku yang dimaksud melanggara dalah perbuatan yang tercela

c. Polisi yang melanggar meminta maaf langsung di hadapan persidangan komisi kode etik POLRI dan dengan permohonan tertulis kepada Kapolri dan yang merasa dirugikan

d. Dapat merugikan instansi

e. Terbukti melakukan perbuatan dan berperilaku yang dapat merugikan dinas Kepolisian;

f. Sanksi administrasi

g. Mengikuti suatu pembinaan yang merupakan tugas Polri yang melanggar kode etik melalui Komisi pelanggaran kode etik

h. Pindah tugas dengan jabatannya yang berbeda, yang bersifat Demosi, minimal satu tahun;

i. Pindah ke fungsi yang berbeda dengan sebelum pelanggaran (demosi), minimal satu tahun;

j. Pindah tugaskan wilayah beda atau disebut Demosi, paling cepat satu stahun;

k. Teguran lisan;

1. Pemberhentian secara tidak dengan hormat (PTDH) sebagai anggota Polri.

Jatuhnya suatu hukuman bisa dihapuskan apabila ada persetujuan dari komisi kode etik profesi Polri dikarenakan oleh pelanggar mengidap suatu penyakit kejiwaan, meninggal dunia. Adanya suatu pertimbangan bahwasanya pelanggaran tesb memang benar dilakukan untuk kepentingan tugasnya dalam kepolisian, masuk akan dan juga patut dalam lingkup jabatan, ataupun juga layak dikarenakan keadaan yang memaksa dengan menghormati HAM.

\section{SIMPULAN DAN SARAN}

\section{Simpulan}

Berdasarkan analisis data, hasil penelitian mengungkapkan bahwa Pengaturan hukum tentang pengamanan pengawalan yakni mengacu kepada suatu aturan tertulis yakni Undang-undang Nomor 22 Tahun 2009 tentang Lalu Lintas dan Angkutan Jalan yang mana terdapat tujuh kendaraan yang bisa untuk memperoleh hak utama yang bisa didahulukan dalam mobilisasi (kegiatan lalu lintas) dan atas suatu kepentingan umum menurut Pasal 134 dan juga berdasarkan Undang-undang Nomor 2 Tahun 2002 tentang Kepolisian Negara Republik Indonesia yang memiliki tugas pokok perlindungan, melayani masyarakat khususnya di jalan raya dan juga mengayomi masyarakat dalam kegiatan lalu lintas. Pada suatu pengamanan atau pengawalan terhadap rombongan VVIP ataupun VIP yakni merupakan tanggung jawab dari instansi Kepolisian. Sanksi yang diterima oleh para anggota Polri jika selama pelaksanaan tugas pengamanan atau pengawalan tidak cakan dan juga selaras dengan Standar Operasional Prosedur yakni kepadanya akan dikenakan sanksi disiplin sebagaimana yang telah diatur dalam Peraturan Pemerintah Republik Indonesia Nomor 2 Tahun 2003 tentang disiplin anggota polri ataupun sanksi pelanggaran komisi kode etik profesi POLRI yang diatur dalam peraturan tertulis, Peraturan Kapolri Nomor 14 Tahun 2011 tentang Kode Etik Profesi Polri.

\section{Saran}

Dari simpulan penelitian di atas, adapun saran yang disampaikan peneliti yaitu diharapkan kepada anggota Polri dalam melakukan pengamanan pengawalan rombongan VVIP maupun VIP hendaknya dalam pelaksanaan tugas harus bekerja berdasarkan dengan Undang-undang yang berlaku. Diharapkan kepada masyarakat sebagai pengguna jalan agar menumbuhkan kesadaran dalam berkendara dengan mengutamakan keselamatan dan mentaati peraturan berlalu lintas. Tujuannyapun untuk menjaga keselamatan berkendara agar terhindar dari kecelakaan lalu lintas dan meningkatkan budaya tertib berlalu lintas saat berkendara dengan mengedepankan disiplin berlalu lintas.

\section{DAFTAR PUSTAKA}

Amiruddin, \& Asikin, H. Z. (2006). Pengantar Metode Penelitian Hukum. Jakarta: Raja Grafindo Persada.

Anas, H. (2020). Police Goes to School Program to Reduce Traffic Violation by Students. Journal Tanggon Kosala, 9(2), 195-224.

Ashshofa, B. (1996). Metode Penelitian Hukum. Jakarta: Rineka Cipta.

Hanafi, M. R. (2017). Optimalisasi Dikmas Lantas oleh Unit Lintas Dikyasa Satuan Lalu Lintas 
Polres Cilacap Guna Meningkatkan Kesadaran Pelajar dalam Keselamatan Berlalu Lintas. Journal Advances in Police Science Research, 1(3), 773-812.

Iskandar, A. (1996). Menuju Lalu Lintas dan Angkutan Jalan yang Tertib. Jakarta: Departemen Perhubungan Indonesia.

Jasmine, N. C. (2020). Pertanggungjawaban Pidana Kecelakaan Lalu Lintas Karena Penggunaan Smartphone Saat Mengemudi. Indonesian Journal of Criminal Law and Criminology (IJCLC), $1(1), 33-44$.

Junef, M. (2014). Perilaku Masyarakat terhadap Operasi Bukti Pelanggaran ( Tilang ) dalam Berlalu Lintas. Jurnal Widya Yustisia, 1(1), 52-60.

Karjadi, M. (1975). Bhayangkara Lalu Lintas dan Angkutan Jalan raya. Bogor. Politeia.

Romadhon, M. I. (2020). Peran Sabhara dalam Mencegah Terjadinya Kericuhan dalam Pesta Demokrasi Pemilu 2019 di Wilayah Hukum Polres Salatiga. Indonesian Journal of Police Studies, 4(1), 359-480

Soekanto, S. (1984). PengantarPenelitianHukum. UI Press. 